\title{
Congenital cutis laxa with retardation of growth and development
}

\author{
M A PATTON*, J TOLMIE $\dagger$, P RUTHNUM,+ S BAMFORTH ,
} M BARAITSER*, AND M PEMBREY*

From ${ }^{*}$ the Department of Clinical Genetics, Institute of Child Health, 30 Guilford Street, London WC1 1EH; †Departments of Paediatrics and Clinical Genetics, Royal Hospital for Sick Children, Yorkhilt, Glasgow; and $¥$ Department of Medical Genetics, University Hospital of Wales, Heath Park, Cardiff.w

SUMMARY Seven patients with congenital cutis laxa are presented. The associated featurés include developmental delay, joint laxity, wide anterior fontanelle, growth retardation, denta caries, and osteopenia. The heterogeneity and inheritance of congenital cutis laxa are discussedir This particular syndrome appears distinct and is likely to be autosomal recessive in view of the two brother-sister sib pairs in this report.

Congenital cutis laxa is a rare disorder characterised by loose, redundant skin present at birth. The condition is heterogeneous. One form of congenital cutis laxa has been reported by Agha et al in association with intrauterine and postnatal growth retardation together with developmental delay, delayed closure of the anterior fontanelle, and ligamentous laxity. Previous reports ${ }^{1-4}$ have predominantly been in girls and it has been suggested that this condition may represent an $\mathrm{X}$ linked dominant. $^{2}$ We report seven new cases including two brother-sister sib pairs suggesting that autosomal recessive inheritance is more likely.

\section{Case reports}

CASE 1 (PEDIGREE A, FIG 1)

This male child was born at 34 weeks' gestation to a

Received for publication 22 April 1986.

Revised version accepted for publication 3 July 1986. non-consanguineous Scottish couple. The father we 17 and the mother was 23 years old. The mother hod a healthy boy and girl from a previous marriage. $\mathrm{HEs}$ birth weight was $2 \cdot 2 \mathrm{~kg}$ (3rd to 10th centile). Loose skin was noted at birth. During the first yeab, developmental delay became evident and his lee then, weight, and head circumference fell below the 3 ird centile for age.

On examination there was redundant lax ski especially over the buttocks and thighs, with genos alised ligamentous laxity and poor muscle bu There was lax facial skin and a facial appearanfe which included a prominent nose, long philtru勇, telecanthus, and an antimongoloid slant of the palpebral fissures (fig 2).

Normal investigations included a skeletal survey, an echoencephalogram, a renal ultrasound examination, EEG, and prometaphase chromosome anafisis. Over the next year he made slow developmental
A
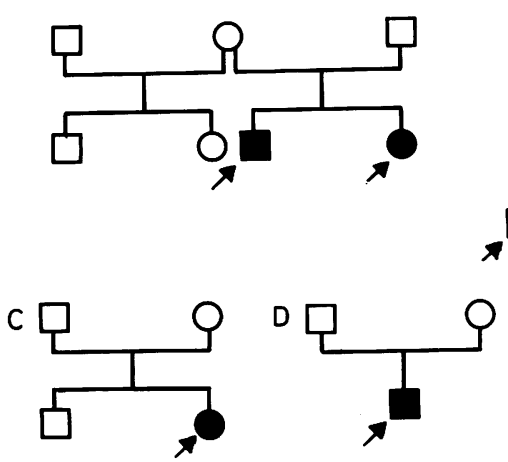

B
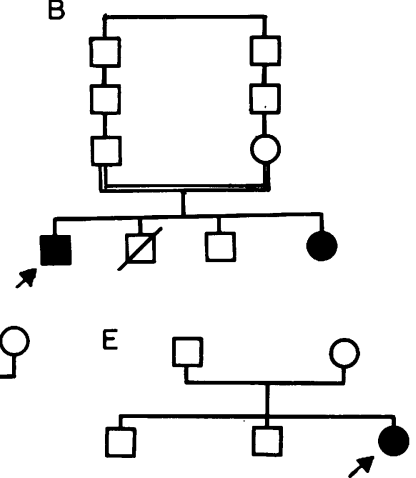

FIG 1 Family pedigrees. Cases 1 and 2 are in N pedigree $A$, cases 3 and 4 are in pedigree $B, N$ case 5 is in pedigree $C$, case 6 is in pedigree $D$. and case 7 is in pedigree $E$. 


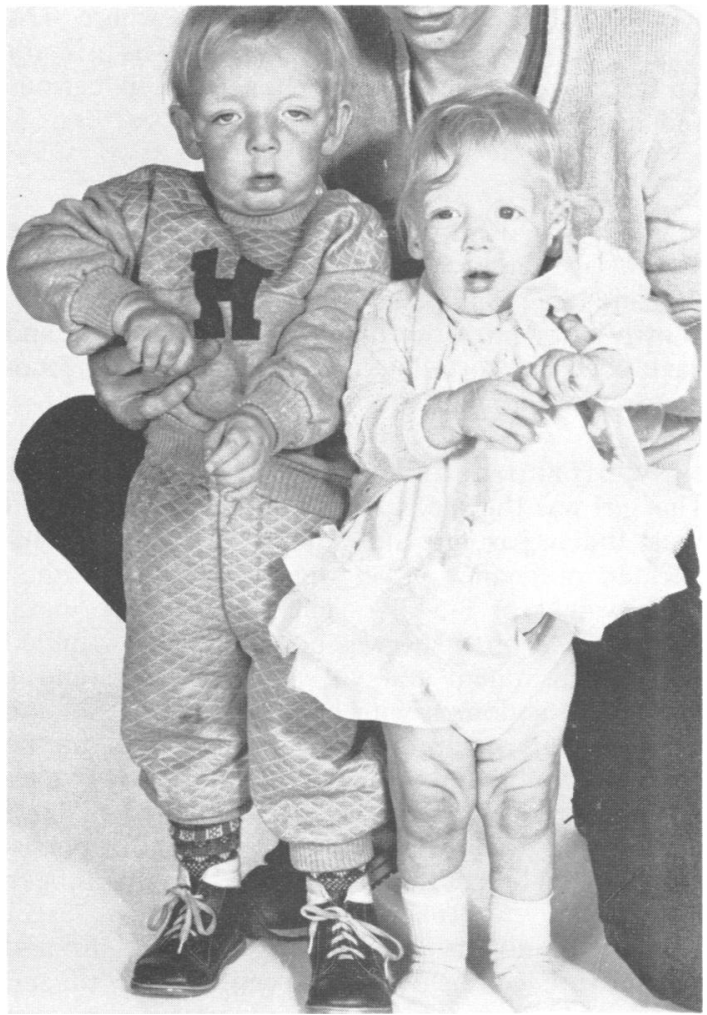

FIG 2 Photograph showing cases 1 and 2. Note the facial appearance with lax skin and increased skin folds around the knees.

progress and his growth continued parallel to but below the 3rd centile. At two years of age he could just walk unsupported and could speak three words. his anterior fontanelle was still open, measuring $2 \times 2$ $\mathrm{cm}$, lax skin was prominent, and he had a genu valgum and pes planus.

CASE 2 (PEDIGREE A, FIG 1)

The sister of case 1 was also born at 34 weeks' gestation; birth weight was $2 \cdot 18 \mathrm{~kg}$ (3rd to 10 th centile), length $48 \mathrm{~cm}(>90$ th centile), and head circumference $30 \mathrm{~cm}$ ( 3 rd to 10 th centile). At birth she was noted to have lax skin and dysmorphic features similar to her brother ( fig 3). By one year of age her length, weight, and head circumference had fallen below the 3 rd centile. Her anterior fontanelle was still widely open, measuring $6 \times 5 \mathrm{~cm}$, and her motor milestones were delayed. At 15 months she was unable to sit unsupported. Like her brother she had poor muscle bulk, pes planus, ligamentous laxity, and loose, redundant skin especially over her

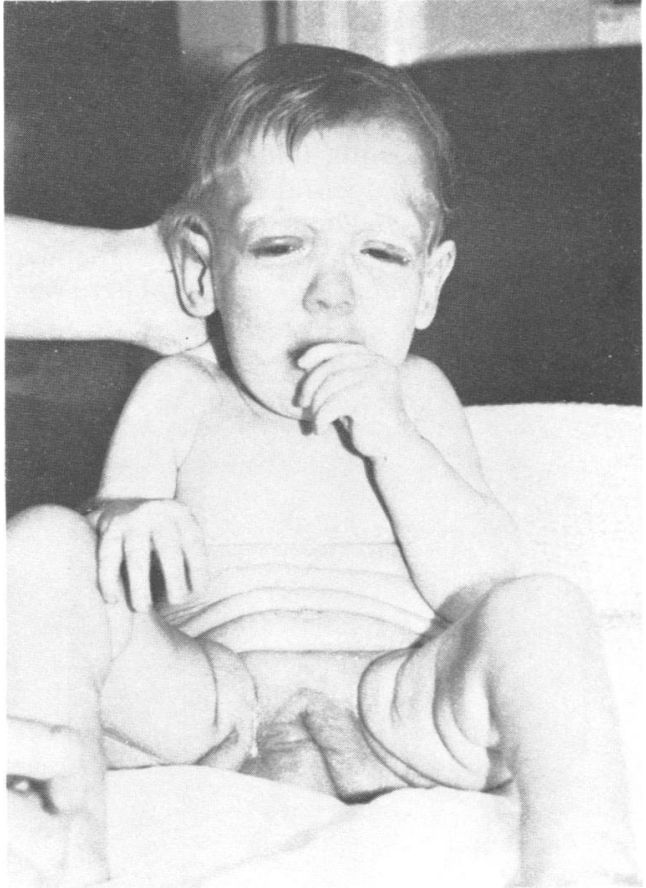

FIG 3 Case 2 showing excessive skin folds and loose skin over abdomen, thighs, and labia in the neonatal period.

abdomen, thighs, and labia (fig 3). She also had a similar facial appearance (fig 2) with lax skin, telecanthus, a prominent nose, and downward slanting palpebral fissures. Cerebral and renal ultrasound and radiographical examination of the pelvis and hips revealed no abnormality. Other investigations which gave normal results included an electrocardiogram, serum creatine kinase, urinary organic acid screen, and prometaphase chromosome analysis.

CASE 3 (PEDIGREE B, FIG 1)

This boy was the first child of second cousin parents from Iraq. The pregnancy was complicated by vomiting and hypertension. He was born around term as a breech delivery. At birth he was noted to have lax, rubbery skin, a very soft skull with a large anterior fontanelle, and a cleft lip.

His psychomotor development has been slow. He sat alone at nine months, crawled at 13 months, and walked at two years. At four and a half years his speech consisted of single words. He began to suffer from grand mal convulsions at three years of age and was having three to four attacks a day before treatment.

At four and a half years his height was on the 50th 
centile $(107 \mathrm{~cm})$ and his head circumference below the 3 rd centile $(47.5 \mathrm{~cm})$. The anterior fontanelle was still open and measured $8 \times 4 \mathrm{~cm}$. His skin was loose especially over the face and abdomen. There were prominent epicanthic folds with hypertelorism, downward slanting palpebral fissures, and a down turned mouth (fig 4). The surgery on the cleft lip had been disrupted by an injury during an epileptic fit and had failed to repair adequately. There was no

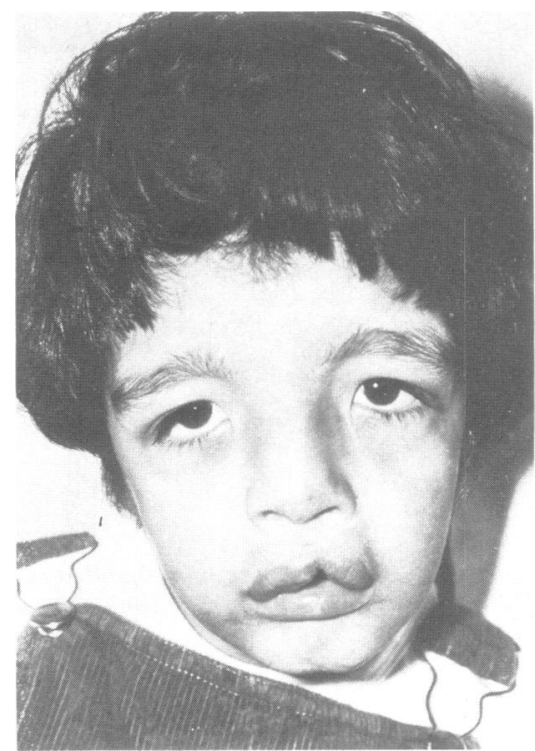

FIG 4 Facial features seen in case 3. The cleft lip was repaired but was traumatised postoperatively leading to a poor cosmetic result. Note the facial appearance associated with lax skin. evidence of abnormal skin healing elsewhere. $\mathrm{H} \stackrel{\mathbb{\Phi}}{\mathbb{\Phi}}$ finger nails were brittle and dystrophic. His primary dentition was incomplete and the teeth were cariots and discoloured (fig 5).

CASE 4 (PEDIGREE B, FIG 1)

This girl is the sister of case 3. She was seen at fir days of age and was noted to have excessive, loose skin and large fontanelles. She had a 'clicky' left hiṕ? Shortly after birth the family returned to Iraq and have been lost to follow up. Details of the psycho: motor development are not known.

CASE 5 (PEDIGREE C, FIG 1)

This girl was the second child of healthy, unrelate West Indian parents. She was born after an unconio plicated pregnancy at 35 weeks' gestation with birth weight of $3.54 \mathrm{~kg}$. There was no perinatæ asphyxia. At birth she was noted to have wrinkleg skin, a prominent tongue, a short neck, and at protruding abdomen with hepatosplenomegaly anf an umbilical hernia. Feeding was difficult in the neonatal period and she developed right lower lobs aspiration pneumonia. She has continued to have difficulty in swallowing with choking and a persis. tent cough. Her psychomotor development has beep delayed.

On examination at two years, her height and weight were well below the 3rd centile $(62.5 \mathrm{~cm}$ ? $6.75 \mathrm{~kg}$ ). However, her head circumference was of the 25 th centile $(47 \mathrm{~cm})$. Her anterior fontanelle was still widely open. She had loose skin especially ov the hands and feet. The facial skin, including the buccal folds, tended to sag. The skin over the palm and soles had an unusual velvety feel due to prominent dermal ridges. The liver was moderate

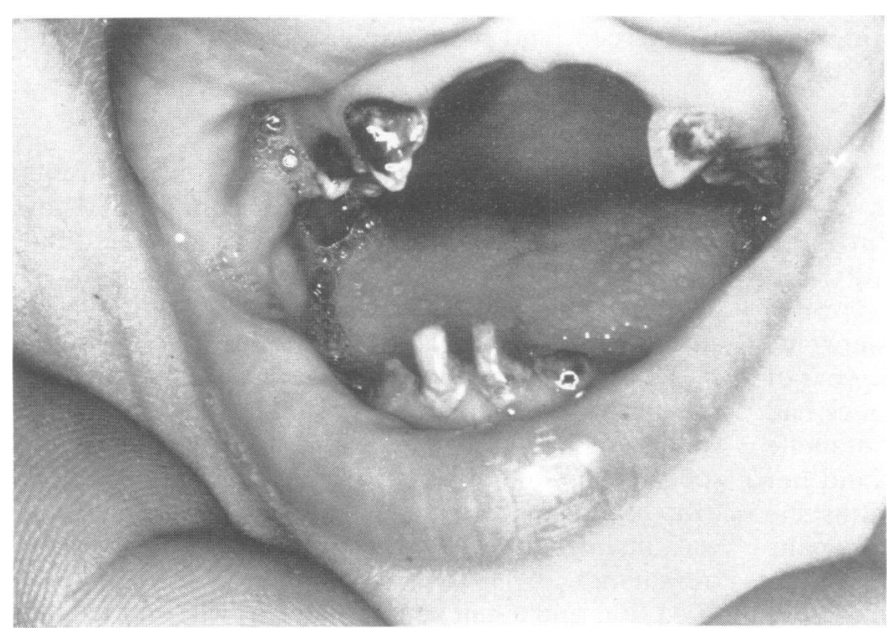


enlarged but the spleen was no longer palpable. Fundal examination was normal. Palatal movement was reduced and she had difficulty in swallowing saliva. The motor tone was increased and the tendon reflexes brisk.

Investigations, including thyroid function tests, plasma amino acids, lysosomal storage enzymes, a mucopolysaccharide screen, and chromosomes, were normal. Radiological investigation showed marked osteoporosis with delayed bone age. There were no joint dislocations. The CT brain scan was normal. An ultrasound scan of the abdomen showed no abnormalities other than mild hepatomegaly. The visual evoked potentials and brain stem auditory evoked potentials showed a reduction in amplitude consistent with impaired central function. The swallowing difficulties were investigated by barium studies and microlaryngoscopy. No anatomical abnormality was seen and it appeared she had a central dysfunction in initiating the swallowing process.

\section{CASE 6 (PEDIGREE D, FIG 1)}

This boy was the first child of Bangladeshi parents. His parents were not known to be related but both came from the same rural village. He was born at 38 weeks' gestation with a birth weight of $2.1 \mathrm{~kg}$. He was noted to have a short neck, epicanthic folds, an umbilical hernia, and loose skin especially over the dorsum of the hands, buccal folds, and neck. There were no-neonatal problems, but in the first seven months he has had recurrent chest infections which required admission to hospital on four occasions.

His height and weight at seven months were well below the 3 rd centile $(59.8 \mathrm{~cm}$ and $5.6 \mathrm{~kg})$ and his head circumference was on the 3 rd centile $(41.5$ $\mathrm{cm})$. He was initially hypotonic and had poor head control. At seven months of age he was able to sit with support.

Investigations showed normal thyroid function, TORCH screen, $\alpha_{1}$ antitrypsin, mucopolysaccharide, and lysosomal enzyme screen, immunoglobulins, and chromosome karyotype. A barium swallow and sweat test were also normal. The skeletal survey showed a generalised osteoporosis with a kyphosis in the dorsolumbar region.

CASE 7 (PEDIGREE E, FIG 1)

This female infant was the third child of nonconsanguineous Caucasian parents from South Wales. The pregnancy was normal, delivery at 39 weeks' gestation was uneventful, and the birth weight was $3.95 \mathrm{~kg}$. At birth, dysmorphic facies, lax skin, and bilateral talipes equinovarus were recorded. The karyotype was $46, \mathrm{XX}$.

Throughout the first two and a half years of life the child failed to thrive. Developmental delay wás obvious at six months of age. The talipes in the right foot responded to serial plaster splints but the left required surgical correction.

On examination at two and a half years her weight was below the $3 \mathrm{rd}$ centile $(8 \cdot 2 \mathrm{~kg})$. The anterior fontanelle was open. The face was asymmetrical and there was bilateral ptosis. The nasal bridge was depressed and the nose upturned. The philtrum was long and the lips thin, and the ears were low set and protruberant. Mild pectus excavatum and sloping shoulders were noted. The hands appeared large and covered with loose fitting skin which formed folds at the wrist, knuckles, and interphalangeal creases. Folds of skin were also observed in the axillary and hip creases. Muscle tone was normal but range of movement in all joints was greatly increased. The hair was sparse and wiry. The teeth were widely spaced, peg-like, and hypocalcified. The incisors and canines were carious with extensive erosion of the crowns, and there was delayed eruption of the molars and premolars. The intellectual development was compatible with an 18 month old infant.

A glucose tolerance test showed a flat response curve. The bone age was delayed. The following investigations were normal: urine and plasma amino acids, urea, electrolytes, liver function tests, capillary gases, haemoglobin and white cell count, urine mucopolysaccharide screen, cranial ultrasound, and serum virology.

\section{Discussion}

Cutis laxa is characterised clinically by redundant, loose skin that distorts the facial features and hangs in folds. Histological studies have shown that there is fragmentation of the elastin fibres, ${ }^{5}$ while collagen fibres and anchoring fibrils in the skin are normal. ${ }^{6}$ Unlike Ehlers-Danlos syndrome, the skin in cutis laxa, although loose, is not hyperextensible. ${ }^{7}$

Congenital cutis laxa is a heterogeneous condition (table). Autosomal dominant cutis laxa usually presents in adult life but may be present from birth. It is not associated with other abnormalities and life span is normal. ${ }^{7}$ An autosomal recessive form of

TABLE Classification of congenital cutis laxa.

\begin{tabular}{ll}
\hline & Reference \\
\hline Cutis laxa (AD) & 7 \\
Cutis laxa and emphysema & 17 \\
$\begin{array}{l}\text { Cutis laxa and growth/mental retardation } \\
\text { Cutis laxa. mental retardation. and }\end{array}$ & $1-4$ \\
$\begin{array}{l}\text { corneal clouding } \\
\text { Cutis laxa and skeletal and genital } \\
\text { abnormalities }\end{array}$ & 8 \\
Cutis laxa and osteoporosis & 9 \\
\hline
\end{tabular}


cutis laxa associated with emphysema and death in childhood has been clearly described. ${ }^{1}$ It does not differ cutaneously from other forms of cutis laxa, but in addition to emphysema it is associated with diaphragmatic hernia and diverticulae of the urinary and gastrointestinal tract. Congenital cutis laxa has also been reported by De Barsey et al ${ }^{8}$ with dementia, growth retardation, and corneal clouding. A 'pseudoathetoid' movement disorder with onset in the second year of life appears to be a striking feature in this form of congenital cutis laxa.

Another single case report by Kaye et al ${ }^{9}$ described cutis laxa in a male infant with digital abnormalities and hypospadias. The types of congenital cutis laxa most relevant to this report are the cutis laxa associated with physical and mental retardation $^{1-4}$ and that associated with osteoporosis. ${ }^{10}$

All the patients in this report had loose skin at birth. This has been associated with a characteristic facial appearance of downward slanting palpebral fissures, broad, flat nasal bridge, anteverted nostrils, sagging cheeks, and large ears. It has been suggested that the shape of the nose is normal in acquired cutis laxa. ${ }^{11}$ Mild developmental delay has been found in all patients, except cases 4 and 6 where follow up from the neonatal period was not possible. The tendency for improved performance to develop with age has been reported, ${ }^{2}$ but we have not had sufficient follow up to confirm this observation. Prenatal growth retardation was present in cases 2 and 6 , while postnatal growth retardation was found in cases $1,2,5,6$, and 7 . In cases 3 and 4 the physical growth was normal during the period of follow up. In case 5 the growth of the head circumference was not as severely affected as linear growth.

One feature which has not been reported with cutis laxa and retardation of growth and development is the presence of osteoporosis. This feature in association with cutis laxa has been previously described as a separate entity. ${ }^{10}$ In cases 5 and 6 there was generalised osteoporosis with delayed bone age in one and a thoracolumbar kyphosis in the other. In case 5 there was considerable psychomotor delay, while in case 6 the patient's psychomotor development is still uncertain. On the basis of this overlap we would suggest that cutis laxa with osteoporosis may be the same entity as cutis laxa with growth and developmental delay.

Another feature which appears to be an associated abnormality in this form of cutis laxa is dental caries. In cases 3 and 7 there was widespread caries with erosion of the dental crowns. The teeth were small, widely spaced, and hypocalcified. This feature has not been reported previously in cutis laxa.
The entity of cutis laxa with retardation of growt and development has been suggested to be an $\mathbb{R}$ linked dominant defect, as 13 out of the 14 case reported previously have been female. ${ }^{2}$ However? the presence of two brother-sister sib pairs in this report suggests that it is more likely to be autosomas recessive. In one of the sib pairs the parents were second cousins from the Middle East.

Following the subclassification of Ehlers-Danlo syndrome, molecular abnormalities in collagen biosynthesis have been defined. A similar understanding of the heterogeneity of cutis laxa ma $\overrightarrow{\mathrm{w}}$ reveal insights into the biology of elastin. Th\& histology of cutis laxa has shown fragmentation of elastin fibres similar to that which is seen with ageing or solar radiation. This has suggested that cutis laxa represents an abnormality in biosynthesis However, one form of cutis laxa, which is X linkegs and presents in childhood, has been shown to bo associated with a decreased lysyl oxidase activity and a reduction in the cross linkage of collagen and elastin fibres during biosynthesis. ${ }^{12}$ It is possible tha some genetic variants of congenital cutis laxa are th result of abnormalities in biosynthesis of elastin either at the level of the gene or in its pos@ transcriptional control. It might now be possible th study this, as a gene for elastin has been isolategle and provisionally localised to the $\mathrm{q} 31 \rightarrow \mathrm{qter}$ regkop of chromosome $2 .{ }^{14}$

We would like to thank Dr Leonard and Professof Brooke for referring case 5, Dr Savage for referrin 9 case 6 , and Dr C Weaver for referring case 7 . W would also like to thank Mrs Melanie Barham foof secretarial assistance.

\section{References}

1 Agha A, Sakati NO, Higginbottom MC, Jones KL, Bay Nyhan WL. Two forms of cutis laxa presenting in the newbor period. Acta Paediatr Scand 1978;67:775-80.

2 Sakati NO, Nyhan WL. Shear CS, et al. Syndrome of cutis laxa ligamentous laxity and delayed development. Pediatric 1983;72:850-6.

${ }^{3}$ Karrar ZA, Elidrissy ATH, Adam KA. Cutis laxa, intrauterine growth retardation and bilateral dislocation of the hips: a reporf of five cases. In: Skeletal dysplasias. New York: Alan R Lis 1982:215-21.

${ }^{4}$ Philip AGS. Cutis laxa with intrauterine growth retardation andu hip dislocation in a male. $J$ Pediatr 1978:93:150-1. or

5 Goltz RW, Hult AM, Goldforb M, Gorlin RJ. Cutis laxa: N manifestation of generalised elastolysis. Arch Dermatơ 1965;92:373-87.

' Hashimoto K. Kanzaki T. Cutis laxa: ultrastructural an $\mathbb{E}$ biochemical studies. Arch Dermatol 1975;111:861-73.

7 Beighton PH. The dominant and recessive forms of cutis laxa. Med Genet 1972;9:216-21.

${ }^{x}$ De Barsey AM. Moens E, Dierckx L. Dwarfism, oligophrenia and degeneration of the elastic tissue in skin and cornea. A new syndrome? Helv Paediatr Acta 1968:23:305-13. 
${ }^{y}$ Kaye CI, Fisher DE, Esterly NB. Cutis laxa, skeletal anomalies and ambiguous genitalia. Am J Dis Child 1974;127:115-7.

11 Sakati NO, Nyhan WL. Congenital cutis laxa and osteoporosis. Am J Dis Child 1983:137:452-4.

11 Beighton PH, Bull JS, Edgerton M. Plastic surgery in cutis laxa. Br J Plast Surg 1970:23:285-90.

12 Byers PH, Siegel RC. Holbrook KA, Narayanan AS, Bornstein P. Hall JG. X linked cutis laxa: defective cross-link formation in collagen due to decreased lysyl oxidase activity. $N$ Engl J Med 1980;303:61-5.
13 Davidson JM, Crystal MD. The molecular aspects of elastin gene expression. J Invest Dermatol 1982:79:133-7s.

14 Emanuel BS, Cannizzaro L, Ornstein-Goldstein N, et al. Chromosomal localisation of the human elastin gene. Am J Hum Genet 1985;37:873-82.

Correspondence and requests for reprints to Dr $\mathbf{M}$ A Patton, Department of Clinical Genetics, St George's Hospital Medical School, Blackshaw Road, London SW17 0QT. 